\title{
Potential of plotting positions for intensity-duration-frequency curves with short rainfall records
}

\author{
Noratiqah Mohd Ariff*, Abdul Aziz Jemain, Mohd Aftar Abu Bakar \\ School of Mathematical Sciences, Faculty of Science and Technology, Universiti Kebangsaan Malaysia, 43600 UKM Bangi, Selangor, Malaysia \\ * Corresponding author: tqah@ukm.edu.my
}

Article history

Received 14 October 2017

Accepted 8 November 2017

\begin{abstract}
Intensity-duration-frequency (IDF) curves represent the relationship between storm intensity, storm duration and return period. The IDF curves available are mostly done by fitting series of annual maximum rainfall intensity to parametric distributions. However, the length of annual rainfall records, especially for small scaled data, are not always enough. Rainfall records of less than 50 years are usually deemed insufficient to unequivocally identify the probability distribution of the annual rainfall. Thus, this study introduces an alternative approach that replaces the need for parametric fitting by using empirical distribution based on plotting positions to represent annual maximum rainfall series. Subsequently, these plotting positions are used to build IDF curves. The IDF curves found are then compared to the IDF curves yielded from the parametric GEV distribution which is a common basis for IDF curves. This study indicates that IDF curves obtained using plotting positions are similar to IDF curves found using GEV distribution for storm events. Hence, researchers could model and subsequently build IDF curves for annual rainfall records of less than 50 years by using plotting positions and avoid any probability distribution fitting of insufficient data.
\end{abstract}

Keywords: Intensity-duration-frequency (IDF), plotting positions, storm events, L-moment

\section{INTRODUCTION}

Extreme rainfall events such as flood which is caused by excessive rain are destructive and hazardous to human lives and properties. Thus, extreme event analysis is performed on rainfall data in order to model and understand the characteristics of these events. Analysis of extreme events can be done by using annual maximum series (AMS) or by partial duration series (PDS) of rainfalls. Both AMS and PDS approaches are commonly used in rainfall studies including those on storms in storm-event analysis (SEA). SEA or event-based analysis has an advantage over conventional moving windows method (window-based analysis) such that the duration of each storm event is not predetermined or fixed. Thus, storms in SEA are said to represent actual rainfalls events [1].

Storm intensity, which is defined as the rate of accumulated rainfall amounts (storm depth) with respect to the length of time (storm duration) for a storm event, must be accurately estimated since underestimation causes excessive damage and overestimation results in excessive cost [2]. It is also important to estimate the frequency of a given storm intensity and the magnitude of storm intensity at a particular recurrence interval. A value which approximates the time interval between storms with similar magnitudes of storm intensity occurring is known as the return period of storm intensity and it could be computed for both AMS and PDS of storms.

The relationship between storm intensity, storm duration and return period proves to be important in constructing and managing water related projects. The mathematical relationship between storm intensity, storm duration and return period is given by the formula for intensity-duration-frequency (IDF) curves [3]. It can be constructed using either the AMS or PDS approaches [4]. The construction of IDF curves are usually done by performing parametric fitting to the series of extreme storm intensities. Parametric fitting assumes that the series of extreme storm intensities follows a type of probability distribution. If this assumption is true, then we could use the mathematical and statistical theory of the distribution in our analysis and inferences. However, if the assumption is incorrect, then our results might be a little misleading. Thus, the restriction of the series belonging to a certain type of distribution can sometimes be too rigid. Another problem with this approach is concerning the sample sizes. Rainfall records of lengths less than 50 years which are typically available for small scaled rainfall data are not so large that it is not enough for the frequency distribution to be unequivocally identified [5].

The objectives of this study are to provide an alternative method in terms of plotting positions to represent rainfall data, to build IDF curves using these plotting positions and to compare the curves obtained with those found from parametric fitting. Thus, in this study, probability plotting positions are used to replace parametric fitting in order to obtain empirical return periods and distributions. Recent studies had examined the goodness of fit for various plotting positions with simulated data following extreme value type I (EV I) [6] and generalized extreme value (GEV) probability distributions [7-9]. The plotting positions are then used to construct IDF curves for eventbased analysis. The IDF curves yield are compared with the ones based on parametric fitting of GEV distribution to determine the degree of loss obtained in using only the empirical distribution. The GEV distribution is chosen due to common practice and it was found to be the best distribution to represent annual maximum storm intensities in Peninsular Malaysia [10]. 


\section{STORM EVENT ANALYSIS (SEA)}

Storm event analysis (SEA) is one of the common methods to observe and extract information from hourly rainfall data. The definition of storm is related to the minimum of inter-event time definition (IETD). The value of IETD is the shortest length of dry period between two consecutive storm events such that the runoff response of successive storms would appear to be independent [11]. If the dry period between two wet hours (hours with rain) is less than the IETD, then the two hours are from the same storm event. If the dry period is more than the IETD, then the two wet hours are considered as parts of two different storms. The IETD value for small urban catchments is six hours because the time concentration of rainfall is usually less than six hours [12]. Fig. 1 shows an illustration for the definition of storms.

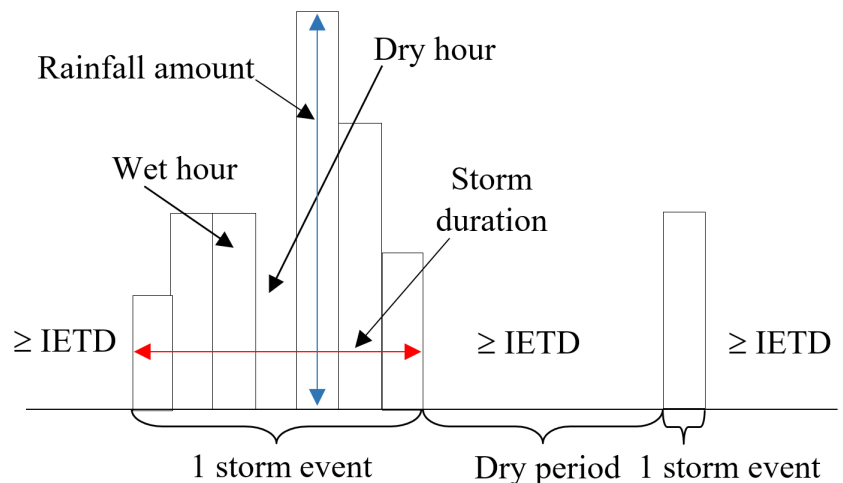

Fig. 1 : Illustration for terminologies in SEA.

Storms in SEA have storm duration and storm depth as their components. Storm duration is the length of time for a rainfall event and storm depth is the accumulated rainfall amount during an event. Storm intensity is the rate of storm depth for a unit of storm duration. A higher value of storm intensity implies a more severe storm which could cause flash floods. Thus, estimation of the return period of extreme storm intensity is often computed in extreme rainfall analysis. A return period of $T$ years specifies that a storm of a particular magnitude of storm intensity is expected to occur, on average, once every $T$ years [13].

Analysis of extreme storm events is of great importance in designing hydraulic structures such as dams and spillways. It can be done by using AMS known as the block maxima approach $[14,15]$ or by PDS from the peak over threshold approach $[16,17]$.

\section{PLOTTING POSITIONS}

Empirical return periods and distributions are obtained by using probability plotting positions. Plotting positions are important in hydrology. They are used to graphically display the systematic records of hydrological series such as AMS [18]. The plotting position estimates the distribution function or the probability of exceedence of these series. Plotting positions also detect outliers and provide the goodness of fit for the fitted distribution [19]. By using empirical approach such as probability plotting positions, we could let the data speak for themselves.

Plotting position formulae have been discussed by hydrologists and statisticians for many years. Various plotting positions have been suggested where most of them are in the form introduced by Cunnane $[20]$ as

$$
F_{r}=\frac{r-p}{n+1-2 p}
$$

with $r$ is the rank of the series in ascending order, $n$ is the length of the series and $p$ is a constant which varies from 0 to 0.5 . Some of the existing plotting positions commonly used in hydrology based on Eq.
Error! Reference source not found. are Weibull $(p=0)$, Adamowski $(p=0.25)$, Gringorten $(p=0.44)$ and Hazen $(p=0.5)$ [21].

Eq. (1) can be written in a more general form as

$$
F_{r}=\frac{r+p}{n-q}
$$

with $r$ is the rank of the series in ascending order and $n$ is the length of the series. Both $p$ and $q$ are constants. Eq. Error! Reference source not found. can then be expressed as

$$
n F_{r}-r=p+q F_{r}
$$

which shows that there is a linear relationship for $\left(n F_{r}-r\right)$. From this equation, Goel and De [7] as well as Kim et al. [8] found unbiased plotting position formulas for the GEV distribution. Most parametric fitting of IDF curves are based on the generalized extreme value (GEV) distribution for AMS and generalized Pareto (GPA) distribution for PDS of storm intensities. For this study, we focused on AMS of storm intensities and hence on GEV distribution.

The GEV distribution consists of extreme value type I, II and III (EV I, EV II and EV III). The cumulative distribution function (CDF) for the GEV distribution is written as [20]

$$
F(x)=\left\{\begin{array}{c}
\exp \left\{-\left[1-\kappa\left(\frac{x-\xi}{\alpha}\right)\right]^{1 / \kappa}\right\}, \kappa \neq 0 \\
\exp \left\{-\exp \left[-\left(\frac{x-\xi}{\alpha}\right)\right]\right\}, \kappa=0
\end{array}\right.
$$

where $\xi \in \mathbb{R}$ is the location, $\alpha>0$ is the scale and $\kappa \in \mathbb{R}$ is the shape parameter respectively. The different types of $\mathrm{EV}$ distribution are based on the value of $\kappa$. EV I has $\kappa=0$, EV II has $\kappa<0$ and EV III has $\kappa>0$. The series will have an upper bound if $\kappa>0$ and thus it is not appropriate for annual maximums [3]. Hence, only EV I and EV II would be considered for the rest of the paper.

Goel and De [7] used regression and found that the most suitable plotting position formula for GEV distribution is

$$
F_{r}=\frac{r-0.02 \gamma-0.32}{n-0.04 \gamma+0.36}
$$

with $\gamma$ is the coefficient of skewness for the GEV distribution. The value of $\gamma$ in this study is estimated by two measures of skewness. The two measures are the Pearson's skewness coefficient, $\gamma_{P}$, which is commonly used for hydrological data, and the L-skewness from the method of L-moments, $\gamma_{L}$.

De [6] developed an unbiased plotting position for EV I distribution using the regression and least square method on Eq. Error! Reference source not found.. The formula yielded is

$$
F_{r}=\frac{r-0.28}{n+0.28}
$$

Meanwhile, Kim et al. [8] uses equation Error! Reference source not found. to obtain another unbiased plotting position formula for GEV distribution based on the real-coded genetic algorithm (RGA) method. The plotting position is given as

$$
F_{r}=\frac{r-0.32}{n+0.0149 \gamma^{2}-0.1364 \gamma+0.3225} .
$$

Similar to Eq. Error! Reference source not found., $\gamma$ is the coefficient of skewness defined as either the Pearson's skewness coefficient or L-skewness. All the plotting positions used for this study are summarized in Table 1.

\section{INTENSITY-DURATION-FREQUENCY (IDF) CURVES}

IDF curves provide the graphical representation of essential statistical summaries of storms [22]. The aim of this study is to construct IDF curves using empirical plotting positions on AMS of 
storm intensities instead of fitting parametric distributions to the series. Storms at each rainfall station are identified and the storms' intensities are grouped with respect to their durations. Hence, each storm group has its respective value of storm duration, $d$. The annual maximum storm intensities for each of these storm groups are obtained and each of these series are put in ascending order.

Table 1 A summary of the plotting positions used in the analysis.

\begin{tabular}{|c|c|c|}
\hline Name & Formula & Abbreviation \\
\hline Weibull & $F_{r}=\frac{r}{r}$ & $\mathrm{~W}$ \\
\hline Adamowski & $F_{r}=\frac{r+1}{r-0.25}$ & A \\
\hline Gringorten & $F_{r}=\frac{\begin{array}{c}n+0.5 \\
r-0.44\end{array}}{r}$ & G \\
\hline Hazen & $F_{r}=\frac{r-0.5}{n}$ & $\mathrm{H}$ \\
\hline & $F_{r}=\frac{r-0.28}{n+0.28}$ & EV I \\
\hline $\begin{array}{l}\text { GEV by } \\
\text { Goel and } \\
\text { De [7] using }\end{array}$ & $F_{r}=\frac{r-0.02 \gamma-0.32}{n-0.04 \gamma_{P}+0.36}$ & $\mathrm{GEV}_{P} 1$ \\
\hline $\begin{array}{l}\gamma_{P} \\
\text { GEV by Kim } \\
\text { et al. [8] } \\
\text { using } \gamma_{P}\end{array}$ & $F_{r}=\frac{r-0.32}{n+0.0149 \gamma_{P}^{2}-0.1364 \gamma_{P}+0.3225}$ & $\mathrm{GEV}_{P 2} 2$ \\
\hline $\begin{array}{l}\text { GEV by } \\
\text { Goel and } \\
\text { De [7] using }\end{array}$ & $F_{r}=\frac{r-0.02 \gamma-0.32}{n-0.04 \gamma_{L}+0.36}$ & $\mathrm{GEV}_{L} 1$ \\
\hline $\begin{array}{l}\gamma_{L} \\
\text { GEV by Kim } \\
\text { et al. [8] } \\
\text { using } \gamma_{L}\end{array}$ & $F_{r}=\frac{r-0.32}{n+0.0149 \gamma_{L}^{2}-0.1364 \gamma_{L}+0.3225}$ & $\mathrm{GEV}_{L} 2$ \\
\hline
\end{tabular}

After determining the value of return period, $T$, which will be used in constructing the IDF curves, the plotting position, $F_{r}$, can then be relate to $T$ by using the following relationship:

$$
F_{r}=1-\frac{1}{T}
$$

The value of $T$ for an empirical distribution such as the plotting position, usually, could not be greater than the length of the series being considered, i.e. the number of years for the annual maximum storm intensities. For a given return period $T$, we can determine the corresponding rank $r$ in the plotting positions. Thus, from the ordered annual maximums in each group of size $n$, we can find the corresponding storm intensity; $i_{r: n}$. A set of $\left(i_{r: n}, d, T\right)$ is obtained for all values of return period $T$ under consideration and for each storm group with storm duration $d$. The sets of $\left(i_{r: n}, d, T\right)$ can be found for all nine plotting positions in Table 1 .

These various sets of $\left(i_{r: n}, d, T\right)$ are then used to obtain the IDF equation based on all the nine plotting positions. In this study, the Sherman IDF equation is used as the IDF equation which is written as [23]:

$$
i=\frac{a T^{\eta}}{(b+d)^{c}}
$$

where $a, \eta, b$ and $c$ are constants and $i$ is the value of storm intensity consisting of either $i_{r: n}$. The least square method is then performed on equation (9) using all the sets of $\left(i_{r: n}, d, T\right)$ to approximate the coefficients $a, \eta, b$ and $c$. Finally, with Eq. (9) and the estimates of $a$, $\eta, b$ and $c$, we can build the IDF curves for storms. The IDF equations are then extrapolated to compute IDF curves for larger return periods such as 50 and 100 years.

The IDF curves obtained from each of the nine plotting positions are compared with those based on parametric fitting of GEV distribution $[10,24]$ which have been commonly used for constructing IDF curves. Comparisons between the IDF curves are done by using three goodness of fit index which are the coefficient of variation of root mean square error, $\mathrm{CV}_{\mathrm{RMSE}}$; the mean percentage of difference, $\Delta ;$ and the coefficient of determination, $R^{2}$.

\section{METHOD FOR THE ANALYSIS OF DIFFERENCES}

The IDF curves based on the plotting positions formulas in Table 1 are compared with the IDF curves obtained by using parametric fitting of GEV distribution. Three measures are used as the goodness of fit for the IDF curves empirically build using plotting positions against the curves based on the GEV distribution. The three measures are the coefficient of variation of root mean square error, $\mathrm{CV}_{\mathrm{RMSE}}$; the mean percentage of difference, $\Delta$; and the coefficient of determination, $R^{2}$. All three measures are calculated in the percentage form for easier interpretation.

The $\mathrm{CV}_{\text {RMSE }}$ is written as

$$
C V_{R M S E}=\frac{\sqrt{\frac{1}{N M} \sum_{j=1}^{N} \sum_{k=1}^{M}\left(x_{d_{j} T_{k}}-z_{d_{j} T_{k}}\right)^{2}}}{\bar{x}} \times 100 \%
$$

with $\bar{x}=\frac{1}{N M} \sum_{j=1}^{N} \sum_{k=1}^{M} x_{d_{j} T_{k}}, x_{d_{j} T_{k}}$ as storm intensities from the curves based on the GEV distribution fitting (observed values) and $z_{d_{j} T_{k}}$ are storm intensities from the curves obtained by using plotting positions for duration $d_{j}$ and return period $T_{k}$. The symbol $N$ refers to the number of various storm durations and $M$ is the number of various return periods. The $\mathrm{CV}_{\text {RMSE }}$ shows the difference between both sets of IDF curves in terms of their root mean square error (RMSE) with respect to the mean of the observed values.

The value of $\Delta$ is calculated as

$$
\Delta=\frac{1}{N M} \sum_{j=1}^{N} \sum_{k=1}^{M} \frac{\left|x_{d_{j} T_{k}}-z_{d_{j} T_{k}}\right|}{x_{d_{j} T_{k}}} \times 100 \% .
$$

As in Eq. (10), the notations $x_{d_{j} T_{k}}$ and $z_{d_{j} T_{k}}$ are storm intensities from the curves based on the GEV distribution and plotting positions respectively for storm duration $d_{j}$ and return period $T_{k}$. The value of $\Delta$ represents the average for the percentage of absolute differences between the two sets of storm intensities with respect to the observed values.

The relationship between the two sets of IDF curves are given by the value of $R^{2}$ as

$$
R^{2}=\frac{\sum_{j=1}^{N} \sum_{k=1}^{M}\left(x_{d_{j} T_{k}-\bar{x}}\right)^{2}-\sum_{j=1}^{N} \sum_{k=1}^{M}\left(x_{d_{j} T_{k}}-\hat{z}_{d_{j} T_{k}}\right)^{2}}{\sum_{j=1}^{N} \sum_{k=1}^{M}\left(x_{d_{j} T_{k}}-\bar{x}\right)^{2}} \times 100 \%
$$

with $\bar{x}=\frac{1}{N M} \sum_{j=1}^{N} \sum_{k=1}^{M} x_{d_{j} T_{k}}$ and $\hat{z}=\beta_{1}+\beta_{2} z$ where $\beta_{1}$ and $\beta_{2}$ are obtained by regression analysis. The terms $x_{d_{j} T_{k}}$ and $z_{d_{j} T_{k}}$ are defined similarly as in Eq. (10) and (11). The measure of $R^{2}$ implies the percentage of variability of $z$ which can be explained by $x$.

\section{CASE STUDY: IDF CURVES BASED ON PLOTTING POSITIONS FOR STORMS IN PENINSULAR MALAYSIA}

Forty five rainfall stations with hourly rainfall data recorded by the Department of Irrigation and Drainage of Malaysia, for the year 1970 to 2008, are used in this study. These stations are located at the edge and middle of Peninsular Malaysia. The coordinates and the geographical plots of the stations are shown in Table 2 and Fig. 2. Hourly rainfall data are used to identify storm events since storms are defined according to the definition of IETD. The value of IETD chosen in this study is six hours.

IDF curves are built using the nine plotting positions listed in Table 1 for the 45 rainfall stations in Peninsular Malaysia by following the steps described in the previous section on IntensityDuration-Frequency (IDF) curves. Each plotting position, $F_{r}$, is substituted into Eq. (8) to get the corresponding estimated parameters of the Sherman equation. Hence, based on these nine plotting positions, nine sets of parameters are approximated for the Sherman equation at each rainfall station. 
Table 2 Code, name, coordinate and data size for hourly rainfalls stations in Peninsular Malaysia.

\begin{tabular}{|c|c|c|c|c|}
\hline \multirow{2}{*}{ Code } & \multirow{2}{*}{ Name } & \multicolumn{2}{|c|}{ Coordinate } & \multirow{2}{*}{$\begin{array}{c}\text { Data Size } \\
\text { (years) }\end{array}$} \\
\hline & & Latitude $(\mathrm{N})$ & Longitude (E) & \\
\hline $\mathrm{J} 1$ & Johor Bahru & $1^{\circ} 28^{\prime} 15^{\prime \prime}$ & $103^{\circ} 45^{\prime} 10^{\prime \prime}$ & 39 \\
\hline $\mathrm{J} 2$ & Kota Tinggi & $1^{\circ} 45^{\prime} 50^{\prime \prime}$ & $103^{\circ} 43^{\prime} 10^{\prime \prime}$ & 35 \\
\hline $\mathrm{J} 4$ & Kluang Mersing & $2^{\circ} 15^{\prime} 25^{\prime \prime}$ & $103^{\circ} 44^{\prime} 10^{\prime \prime}$ & 39 \\
\hline M4 & Chinchin & $2^{\circ} 17^{\prime} 20^{\prime \prime}$ & $102^{\circ} 29^{\prime} 30^{\prime \prime}$ & 39 \\
\hline $\mathrm{J} 5$ & Labis & $2^{\circ} 23^{\prime} 05^{\prime \prime}$ & $103^{\circ} 01^{\prime} 00^{\prime \prime}$ & 39 \\
\hline N1 & Johol & $2^{\circ} 36^{\prime} 10^{\prime \prime}$ & $102^{\circ} 19^{\prime} 10^{\prime \prime}$ & 56 \\
\hline J6 & Endau & $2^{\circ} 39^{\prime} 00^{\prime \prime}$ & $103^{\circ} 37^{\prime} 15^{\prime \prime}$ & 39 \\
\hline N2 & Rompin & $2^{\circ} 43^{\prime} 10^{\prime \prime}$ & $102^{\circ} 30^{\prime} 45^{\prime \prime}$ & 39 \\
\hline N3 & Seremban & $2^{\circ} 44^{\prime} 15^{\prime \prime}$ & $101^{\circ} 57^{\prime} 20^{\prime \prime}$ & 39 \\
\hline N4 & Kg. Sawah Lebar & $2^{\circ} 45^{\prime} 20^{\prime \prime}$ & $102^{\circ} 15^{\prime} 50^{\prime \prime}$ & 39 \\
\hline $\mathrm{Pg} 1$ & Chanis & $2^{\circ} 48^{\prime} 46^{\prime \prime}$ & $102^{\circ} 56^{\prime} 16^{\prime \prime}$ & 29 \\
\hline S1 & Sungai Manggis & $2^{\circ} 49^{\prime} 35^{\prime \prime}$ & $101^{\circ} 32^{\prime} 30^{\prime \prime}$ & 39 \\
\hline S2 & Semenyih & $2^{\circ} 53^{\prime} 55^{\prime \prime}$ & $101^{\circ} 52^{\prime} 13^{\prime \prime}$ & 39 \\
\hline N5 & Petaling & $2^{\circ} 56^{\prime} 40^{\prime \prime}$ & $102^{\circ} 03^{\prime} 55^{\prime \prime}$ & 39 \\
\hline Pg2 & Kepasing & $3^{\circ} 01^{\prime} 15^{\prime \prime}$ & $102^{\circ} 49^{\prime} 55^{\prime \prime}$ & 33 \\
\hline S3 & Ampang & $3^{\circ} 09^{\prime} 00^{\prime \prime}$ & $101^{\circ} 45^{\prime} 00^{\prime \prime}$ & 39 \\
\hline W1 & Edinburgh & $3^{\circ} 10^{\prime} 48^{\prime \prime}$ & $101^{\circ} 37^{\prime} 48^{\prime \prime}$ & 32 \\
\hline W2 & Genting Klang & $3^{\circ} 13^{\prime} 48^{\prime \prime}$ & $101^{\circ} 45^{\prime} 00^{\prime \prime}$ & 37 \\
\hline W3 & Kuala Sleh & $3^{\circ} 15^{\prime} 36^{\prime \prime}$ & $101^{\circ} 46^{\prime} 12^{\prime \prime}$ & 30 \\
\hline W4 & Kg. Sungai Tua & $3^{\circ} 16^{\prime} 12^{\prime \prime}$ & $101^{\circ} 40^{\prime} 48^{\prime \prime}$ & 37 \\
\hline W5 & Gombak & $3^{\circ} 17^{\prime} 35^{\prime \prime}$ & $101^{\circ} 43^{\prime} 55^{\prime \prime}$ & 37 \\
\hline S4 & Kalong Tengah & $3^{\circ} 26^{\prime} 18^{\prime \prime}$ & $101^{\circ} 39^{\prime} 41^{\prime \prime}$ & 31 \\
\hline $\mathrm{Pg} 3$ & Pekan & $3^{\circ} 33^{\prime} 39^{\prime \prime}$ & $103^{\circ} 21^{\prime} 25^{\prime \prime}$ & 39 \\
\hline $\mathrm{Pk} 1$ & Tanjung Malim & $3^{\circ} 41^{\prime} 00^{\prime \prime}$ & $101^{\circ} 31^{\prime} 25^{\prime \prime}$ & 37 \\
\hline S5 & Sungai Bernam & $3^{\circ} 54^{\prime} 14^{\prime \prime}$ & $101^{\circ} 21^{\prime} 00^{\prime \prime}$ & 39 \\
\hline $\mathrm{Pg} 4$ & Paya Kangsar & $3^{\circ} 54^{\prime} 14^{\prime \prime}$ & $102^{\circ} 25^{\prime} 58^{\prime \prime}$ & 39 \\
\hline Pk2 & Teluk Intan & $4^{\circ} 01^{\prime} 00^{\prime \prime}$ & $101^{\circ} 02^{\prime} 10^{\prime \prime}$ & 38 \\
\hline Pk3 & Ladang Bikam & $4^{\circ} 02^{\prime} 55^{\prime \prime}$ & $101^{\circ} 18^{\prime} 00^{\prime \prime}$ & 38 \\
\hline Pk4 & Sitiawan & $4^{\circ} 13^{\prime} 05^{\prime \prime}$ & $100^{\circ} 42^{\prime} 00^{\prime \prime}$ & 38 \\
\hline T1 & Kemaman & $4^{\circ} 13^{\prime} 55^{\prime \prime}$ & $103^{\circ} 25^{\prime} 20^{\prime \prime}$ & 39 \\
\hline Pk5 & Kampar & $4^{\circ} 18^{\prime} 20^{\prime \prime}$ & $101^{\circ} 09^{\prime} 20^{\prime \prime}$ & 34 \\
\hline T2 & Dungun & $4^{\circ} 45^{\prime} 45^{\prime \prime}$ & $103^{\circ} 25^{\prime} 10^{\prime \prime}$ & 39 \\
\hline Kn1 & Gua Musang & $4^{\circ} 52^{\prime} 45^{\prime \prime}$ & $101^{\circ} 58^{\prime} 10^{\prime \prime}$ & 38 \\
\hline $\mathrm{Kn} 2$ & Kg. Aring & $4^{\circ} 56^{\prime} 15^{\prime \prime}$ & $102^{\circ} 21^{\prime} 10^{\prime \prime}$ & 34 \\
\hline T3 & Kg. Dura & $5^{\circ} 04^{\prime} 00^{\prime \prime}$ & $102^{\circ} 56^{\prime} 30^{\prime \prime}$ & 38 \\
\hline Kn3 & Bertam & $5^{\circ} 08^{\prime} 45^{\prime \prime}$ & $102^{\circ} 02^{\prime} 55^{\prime \prime}$ & 39 \\
\hline Kn4 & Dabong & $5^{\circ} 22^{\prime} 40^{\prime \prime}$ & $102^{\circ} 00^{\prime} 55^{\prime \prime}$ & 38 \\
\hline PP2 & Sungai Pinang & $5^{\circ} 23^{\prime} 30^{\prime \prime}$ & $100^{\circ} 12^{\prime} 45^{\prime \prime}$ & 39 \\
\hline PP3 & Bukit Bendera & $5^{\circ} 25^{\prime} 25^{\prime \prime}$ & $100^{\circ} 16^{\prime} 15^{\prime \prime}$ & 34 \\
\hline T5 & Batu Hampar & $5^{\circ} 26^{\prime} 50^{\prime \prime}$ & $102^{\circ} 48^{\prime} 55^{\prime \prime}$ & 31 \\
\hline Kh1 & Baling & $5^{\circ} 35^{\prime} 00^{\prime \prime}$ & $100^{\circ} 44^{\prime} 10^{\prime \prime}$ & 31 \\
\hline T6 & Besut & $5^{\circ} 38^{\prime} 35^{\prime \prime}$ & $102^{\circ} 37^{\prime} 20^{\prime \prime}$ & 25 \\
\hline Kh2 & Jeniang & $5^{\circ} 48^{\prime} 50^{\prime \prime}$ & $100^{\circ} 37^{\prime} 55^{\prime \prime}$ & 39 \\
\hline Kh3 & Alor Setar & $6^{\circ} 06^{\prime} 20^{\prime \prime}$ & $100^{\circ} 23^{\prime} 30^{\prime \prime}$ & 39 \\
\hline Kh4 & Kuala Nerang & $6^{\circ} 15^{\prime} 15^{\prime \prime}$ & $100^{\circ} 36^{\prime} 45^{\prime \prime}$ & 31 \\
\hline
\end{tabular}

The averages for the approximated parameters for all 45 stations are given in Table 3. The averages for the approximated parameters of the Sherman equation obtained by using the GEV distribution are also given in Table 3 for comparison purposes.

Table 3 Average for the approximated parameters of the Sherman equation for 45 rainfall stations in Peninsular Malaysia based on plotting positions and GEV distribution.

\begin{tabular}{ccccc}
\hline $\begin{array}{c}\text { Plotting Position/ } \\
\text { Distribution }\end{array}$ & $a$ & $e$ & $b$ & $c$ \\
\hline W & 41.119 & 0.249 & 1 & 0.749 \\
A & 39.324 & 0.256 & 1 & 0.746 \\
G & 38.755 & 0.255 & 1 & 0.744 \\
H & 38.698 & 0.253 & 1 & 0.743 \\
EV I & 38.189 & 0.258 & 1 & 0.743 \\
GEV $_{P}$ & 38.874 & 0.234 & 1 & 0.731 \\
GEV $_{P}$ & 38.024 & 0.258 & 1 & 0.742 \\
GEV $_{L} 1$ & 38.239 & 0.262 & 1 & 0.745 \\
GEV $_{L} 2$ & 38.180 & 0.264 & 1 & 0.746 \\
GEV distribution & 40.277 & 0.248 & 1 & 0.745 \\
\hline
\end{tabular}

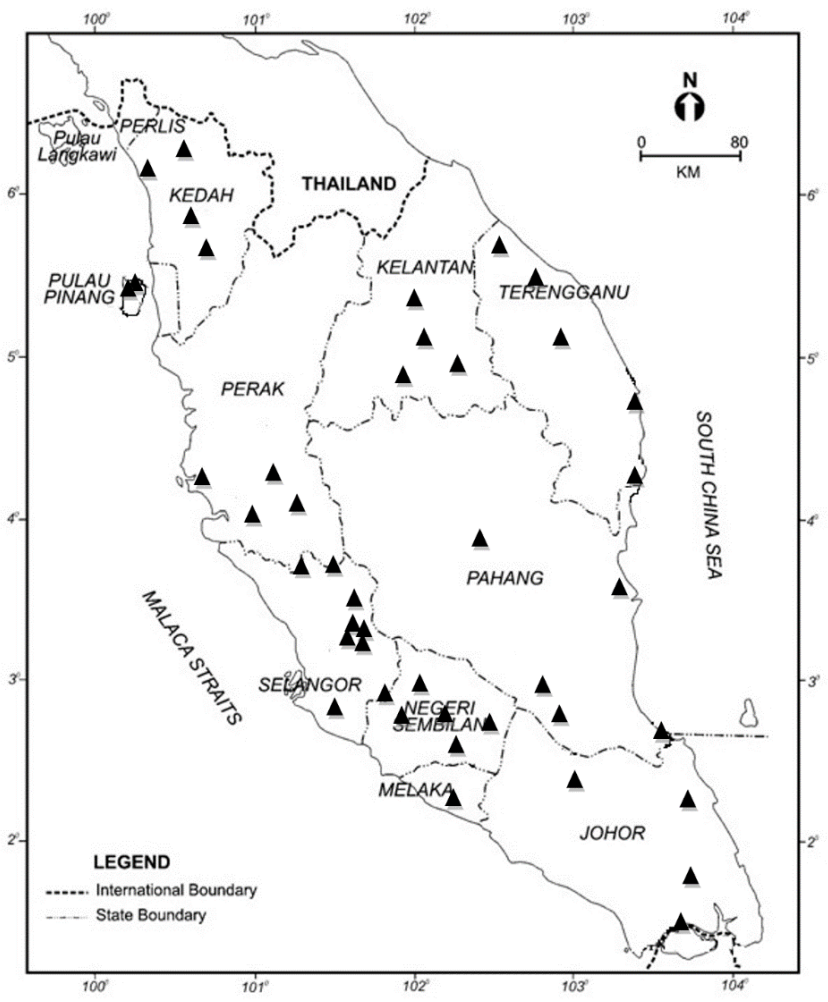

Fig. 2 Locations of hourly rainfalls stations in Peninsular Malaysia used in this study.

On average, the parameters obtained from various plotting positions are within a small range of values and the values of each parameter for different plotting positions are close with one another. The average value for the approximated parameter $b$ is one for all plotting positions irrespective of the plotting position used or the rainfall station being studied. The parameters for the Sherman equation obtained based on plotting positions showed values close to the parameters obtained using the GEV distribution. In fact, all these values are within one standard deviation of the mean for all the four parameters of the Sherman equation found using GEV distribution. From the pattern and the values of the parameters, we can deduced that by purely using empirical methods, we could produce the Sherman equation for IDF curves similar to the ones obtained by fitting GEV distribution to AMS of storm intensities.

With the estimated parameters of Sherman equation, the IDF curves can be constructed for each station by computing the storm intensity for storm of a given duration $d$ and known return period $T$. The storm intensity $i$ is obtained by substituting the values of the parameters as well as the desired $d$ and $T$ into Eq. (9). Comparisons between the values of $i$ obtained from the IDF curves based on each plotting position and the values found from the IDF curves based on GEV distribution are done by calculating the three measures of the analysis of differences stated previously; $\mathrm{CV}_{\mathrm{RMSE}}, \Delta$ and $R^{2}$. The mean and median of the three measures for all 45 stations are given in Table 4.

Table 4 Mean and median for the three goodness of fit index (\%) being studied.

\begin{tabular}{ccccccc}
\hline Plotting & \multicolumn{3}{c}{ Mean } & \multicolumn{3}{c}{ Median } \\
\cline { 2 - 5 } \cline { 6 - 7 } Position & $\mathrm{CV}_{\text {RMSE }}$ & $\Delta$ & $R^{2}$ & $\mathrm{CV}_{\text {RMSE }}$ & $\Delta$ & $R^{2}$ \\
\hline W & 7.685 & 4.690 & 99.811 & 5.491 & 4.016 & 99.901 \\
A & 7.360 & 4.536 & 99.779 & 4.947 & 3.654 & 99.884 \\
G & 7.664 & 4.767 & 99.792 & 6.025 & 4.072 & 99.901 \\
H & 7.509 & 4.753 & 99.807 & 6.211 & 3.871 & 99.904 \\
EV I & 7.585 & 4.883 & 99.791 & 6.197 & 4.175 & 99.910 \\
GEV 1 & 10.578 & 6.121 & 99.596 & 7.658 & 4.883 & 99.879 \\
GEV $_{P} 2$ & 7.609 & 4.901 & 99.781 & 6.329 & 4.284 & 99.893 \\
GEV $_{L} 1$ & 7.550 & 4.834 & 99.758 & 5.992 & 4.109 & 99.855 \\
GEV $_{L} 2$ & 7.440 & 4.752 & 99.759 & 5.881 & 4.142 & 99.850 \\
\hline
\end{tabular}


In overall, the values of $\mathrm{CV}_{\mathrm{RMSE}}$ and $\Delta$ are small for the majority of rainfall stations under study with values less than 15 percent for $\mathrm{CV}_{\mathrm{RMSE}}$ and less than ten percent for $\Delta$. This indicates that building IDF curves solely using empirical equations and distributions for storms in Peninsular Malaysia provide similar results to constructing IDF curves by using parametric fitting.

The close relationship between the set of IDF curves based on plotting positions and the curves found based on GEV distribution can be seen by the values of $R^{2}$ where almost all the stations show values of $R^{2}$ more than 99 percent. This implies that almost all the variation in the IDF curves based on plotting positions can be explained and determined by the IDF curves based on GEV distribution. Fig. 3 shows two examples of the similarity of IDF curves obtained from plotting position $\mathrm{A}, \mathrm{GEV}_{L} 2$ and $\mathrm{H}$ with the IDF curves found with GEV distribution. Based on Fig. 3, the storm intensities found from IDF curves build by using plotting positions $A, G E V_{L} 2$ and $\mathrm{H}$, have values close to the values of storm intensities from the IDF curves obtained using GEV distribution for storm durations ranging from one hour to 30 hours and for return periods of 2, 5, 10, 25, 50 and 100 years.

S3

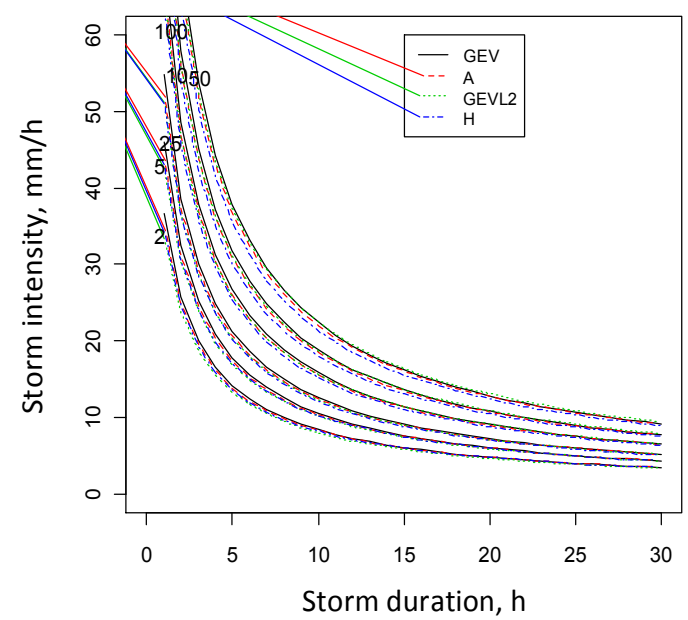

(a)

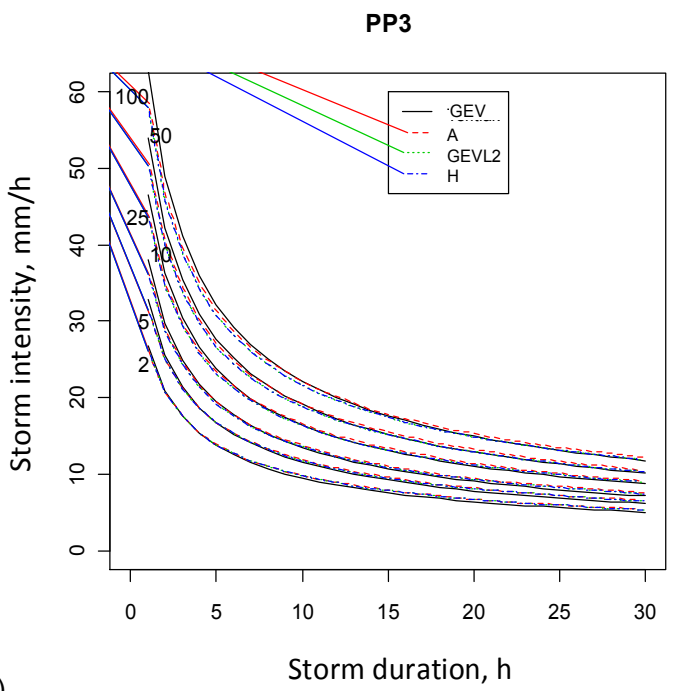

(b)

Note: Values at the end of each curve refers to the value of $T$ for the said curve.

Fig. 3 Comparisons between IDF curves based on plotting positions and IDF curves based on GEV distribution for rainfall station (a) Ampang (S3) and (b) Bukit Bendera (PP3).

\section{CONCLUSIONS}

Most IDF curves obtained for rainfalls data used the fittings of parametric distribution. However, most rainfalls stations have rainfalls data less than 50 years, especially for small scaled data. Hence, the data available is not enough to unequivocally identify the correct distribution to be used in the fitting of parametric distribution to annual maximum series of the data. Furthermore, constructing IDF curves using storm events is seldom done and building IDF curves solely using empirical distributions and equations is not often looked at thoroughly.

In this study, plotting positions are used as a substitute to parametric distribution for obtaining the distribution of the annual maximum storm intensities with various storm durations in order to build IDF curves empirically. All nine plotting positions give similar approximations for the parameters of the Sherman equation. These approximations are within one standard deviation of the mean for the parameters approximated using GEV distribution. Hence, as a direct result of this, the IDF curves obtained using plotting positions are similar to the curves found based on GEV distribution. This is further clarified when the mean and the median of three goodness of fit indexes; the coefficient of variation of root mean square error, $\mathrm{CV}_{\mathrm{RMSE}}$; the mean percentage of difference, $\Delta$; and the coefficient of determination, $R^{2}$; show small differences between values of storm intensities obtained from the curves based on each plotting position with the IDF curves based on GEV distribution.

Overall, the differences between storm intensities found from IDF curves based on plotting positions and storm intensities obtained from IDF curves based on GEV distribution are small. Hence, this study shows that constructing IDF curves using empirical distributions and equations are suitable as an alternative to represent the relationship of storm intensity, duration and return period of extreme storm events.

\section{ACKNOWLEDGEMENTS}

The authors would like to express great gratitude to the Department of Irrigation and Drainage Malaysia for providing hourly rainfalls data for the use of the study. Utmost appreciations to the Ministry of Education (MOE) and to Universiti Kebangsaan Malaysia for the allocation of the research grants (FRGS/1/2014/SG04/UKM/03/2 and GGPM-2015-026) and the facilities used for this research.

\section{REFERENCES}

[1] Olsson, J. and Burlando, P. Reproduction of temporal scaling by a rectangular pulse rainfall model. Hydrological Processes. 2002. 16(3): 611-630.

[2] Ellouze, M. and Abida, H. Regional flood frequency analysis in Tunisia: Identification of regional distributions. Water Resources Management. 2008. 22(8): 943-957.

[3] Koutsoyiannis, D., Kozonis, D. and Manetas, A. A mathematical framework for studying rainfall intensity-duration-frequency relationships. Journal of Hydrology. 1998. 206(1-2): 118-135.

[4] Chang, K. B., Lai, S. H. and Othman, F. Comparison of annual maximum and partial duration series of derivation of rainfall intensity-durationfrequency relationships in Peninsular Malaysia. Journal of Hydrologic Engineering. 2015. 21(1): 05015013.

[5] Hosking, J. R. M. and Wallis, J. R. Regional frequency analysis: An approach based on L-moments. 2005. Cambridge: Cambridge University Press.

[6] De, M. A new unbiased plotting position formula for Gumbel distribution. Stochastic Environmental Research and Risk Assessment. 2000. 14(1): 1-7.

[7] Goel, N. K. and De, M. Development of unbiased plotting position formula for general extreme value distributions. Stochastic Hydrology and Hydraulics. 1993. 7(1): 1-13.

[8] Kim, S., Shin, H., Joo, K. and Heo, J. H. Development of plotting position for the general extreme value distribution. Journal of Hydrology. 2012. 475: 259-269.

[9] Kim, D., Olivera, F., Cho, H. and Lee, S. O. Effect of the inter-annual variability of rainfall statistics on stochastically generated rainfall time 
series: part 1. Impact on peak and extreme rainfall values. Stochastic Environmental Research and Risk Assessment. 2013. 27: 1601-1610.

[10] Ariff, N. M., Jemain, A. A. and Bakar, M. A. A. Pengitlakan lengkung IDF untuk peristiwa ribut ekstrim di Semenanjung Malaysia. Journal of Quality Measurement and Analysis. 2015. 11(2): 31-46.

[11] Bezak, N., Šraj, M. and Mikoš, M. Copula-based IDF curves and empirical rainfall thresholds for flash floods and rainfall-induced landslides. Journal of Hydrology. 2016. 541: 272-284.

[12] Palynchuk, B. and Guo, Y. Threshold analysis of rainstorm depth and duration statistics at Toronto, Canada. Journal of Hydrology. 2008. 348(3-4): 535-545.

[13] Leahy, P. G. and Kiely, G. Short duration rainfall extremes in Ireland: influence of climatic variability. Water Resources Management. 2011 25(3): 987-1003.

[14] De Michele, C., Zenoni, E., Pecora, S. and Rosso, R. Analytical derivation of rain intensity-duration-area-frequency relationships from event maxima. Journal of Hydrology. 2011. 399(3-4): 385-393.

[15] Villarini, G., Smith, J. A., Baeck, M. L., Vitolo, R., Stephenson, D. B. and Krajewski, W. F. On the frequency of heavy rainfall for the midwest of the United States. Journal of Hydrology. 2011. 400(1-2): 103-120.

[16] Ben-Zvi, A. Rainfall intensity-duration-frequency relationships derived from large partial duration series. Journal of Hydrology. 2009. 367(1-2): 104-114.

[17] Nadarajah, S. and Shiau, J. T. Analysis of extreme flood events for the Pachang River, Taiwan. Water Resources Management. 2005. 19(4): 363-374.
[18] Guo, S. L. Unbiased plotting position formulae for historical floods. Journal of Hydrology. 1990. 121(1): 45-61.

[19] Jones, D. A. Plotting positions via maximum-likelihood for a nonstandard situation. Hydrology and Earth System Sciences Discussions. 1997. 1(2): 357-366.

[20] Cunnane, C. Unbiased plotting positions - a review. Journal of Hydrology. 1978. 37(3): 205-222.

[21] Rao, A. R. and Hamed, K. Flood frequency analysis. Florida: CRC Press. 1999.

[22] Gerold, L. A. and Watkins, D. W. Short duration rainfall frequency analysis in Michigan using scale-invariance assumptions. Journal of Hydrologic Engineering. 2005. 10(6): 450-457.

[23] Nhat, L. M., Tachikawa, Y. and Takara, K. Establishment of intensityduration-frequency curves for precipitation in the monsoon area of Vietnam. Annuals of Disaster Prevention Research Institute, Kyoto University 2006. 49 B: 93-102. Retrieved from http://www.dpri.kyoto-u.ac.jp/nenpo/no49/49b0/a49b0p09.pdf.

[24] Ariff, N. M., Jemain, A. A. and Bakar, M. A. A. Regionalization of IDF curves with L-moments for storm events. International Journal of Mathematical, Computational, Physical, Electrical and Computer Engineering. 2016. 10(5): 172-178. 